\title{
Potential role for nectin-4 in the pathogenesis of pre-eclampsia: a molecular genetic study
}

\author{
Mayuko Ito 1,2, Haruki Nishizawa ${ }^{1 *} \mathbb{D}$, Makiko Tsutsumi ${ }^{2}$, Asuka Kato ${ }^{1}$, Yoshiko Sakabe ${ }^{1,2}$, Yoshiteru Noda 1,2, \\ Akiko Ohwaki ${ }^{1,2}$, Jun Miyazaki ${ }^{1,2}$, Takema Kato ${ }^{2}$, Kazuya Shiogama ${ }^{3}$, Takao Sekiya', Hiroki Kurahashi \\ and Takuma Fujii
}

\begin{abstract}
Background: Nectins are cell adhesion molecules that play a pivotal role in adherens junctions and tight junctions. Our previous study using whole-genome oligonucleotide microarrays revealed that nectin-4 was upregulated in pre-eclamptic placentas. We investigated the role of nectin- 4 in the etiology of pre-eclampsia.

Methods: We investigated the expression of nectin-4 using real-time RT-PCR, western blot and immunostaining. Additionally, we performed matrigel invasion assay and cytotoxicity assay using cells overexpressing the nectin-4.

Results: NECTIN4 transcripts were elevated in pre-eclamptic placentas relative to uncomplicated pregnancies. Nectin-4 protein levels in pre-eclamptic placentas were higher on a semi-quantitative western blot. Nectin-4 was localized at the apical cell membrane in syncytiotrophoblast cells and not at the adherens junctions. Nectin-4 was also detected in cytotrophoblasts and a subset of cells in the decidua. Nectin-4 overexpressing trophoblast cells migrated normally in the matrix. However, Natural killer (NK) cells showed a strong cytotoxic effect against nectin-4 overexpressing trophoblast cells. No causative genetic variation was evident in the NECTIN4 gene from a pre-eclamptic placenta.
\end{abstract}

Conclusions: There are as yet unknown factors that induce nectin-4 overexpression in trophoblast cells that may contribute to abnormal placentation via an aberrant immune response and the onset of a preeclamptic pregnancy.

Keywords: Nectin-4, Pre-eclampsia, Trophoblast

\section{Background}

Pre-eclampsia is one of the most common obstetrical problems and accounts for almost $15 \%$ of pregnancyassociated disorders. Pre-eclampsia is simply defined by a pregnancy-induced hypertension with proteinuria [1], but is actually not a simple disorder as it involves multiple organs including the liver, kidneys, lungs, coagulation and neural systems. There is now an emerging consensus that pre-eclampsia is a complex polygenetic trait in which maternal and fetal genes, as well as environmental factors, contribute to its onset [2-4].

\footnotetext{
* Correspondence: nharuki@fujita-hu.ac.jp

${ }^{1}$ Department of Obstetrics and Gynecology, Fujita Health University School of Medicine, 1-98 Dengakugakubo, Kutsukake, Toyoake, Aichi 470-1192, Japan

Full list of author information is available at the end of the article
}

Accumulating evidence has also now indicated that the aberrant expression of placental microRNAs is involved in the pathogenesis of pre-eclampsia $[5,6]$. Further to this, the pathogenetic processes underlying this disorder involve numerous factors such as oxidative stress, endothelial dysfunction, vasoconstriction, metabolic changes, thrombotic disorders and inflammatory responses, although the precise mechanisms have remained elusive $[7,8]$.

Nectins are $\mathrm{Ca} 2$ +-independent, immunoglobulin- like cell adhesion molecules that play a pivotal role in both adherens junctions and tight junctions [9]. Nectins were originally described as homologs of poliovirus receptorlike receptors (PVRL) [10]. Some of these molecules interact with the domain of the filamentous-actin (F-actin)-associated molecule (known as afadin) and are 
involved in signal transduction [11]. Although nectin-1, 2 and 3 have been biologically well characterized as adhesion molecules, the functional properties of nectin- 4 are still unknown. Recently, nectin-4 has been demonstrated to be an epithelial receptor for the measles virus [12]. In addition, since certain cancers, (breast, lung and ovarian cancer) overexpress nectin-4, it has been described as a new biomarker for these cancer types [13-15].

We previously performed gene expression profiling of placental tissue from women with and without preeclampsia using whole-genome oligonucleotide microarrays $[16,17]$. Our results from these analyses subsequently identified $\sim 150$ genes with significantly altered expression in pre-eclampsia. NECTIN4 was identified as one of the most significantly upregulated of these genes in pre-eclamptic placentas. In our current study, we have examined the localization of the nectin- 4 protein in placental tissues. We then compared the nectin- 4 protein levels between women with uncomplicated pregnancies and women with severe pre-eclampsia. Further, we performed some functional assays using nectin-4 overexpressing trophoblast cells. Our present findings provide some additional insights into the role of nectin-4 in the etiology of pre-eclampsia.

\section{Methods}

\section{Samples}

All of the clinical samples analyzed in this study were collected at the Department of Obstetrics and Gynecology,
Fujita Health University Hospital, Japan. Placental biopsy samples were obtained during Caesarean sections from both normotensive pregnancy $(n=20)$ and those with severe pre-eclampsia $(n=20)$. Severe pre-eclampsia was defined as a systolic blood pressure of $160 \mathrm{mmHg}$ or higher, or diastolic blood pressure of $110 \mathrm{mmHg}$ or higher on two occasions at least $4 \mathrm{~h}$ apart while the patient is on bed rest (unless antihypertensive therapy is initiated before this time) [18]. Normotensive subjects were matched for maternal age, gestational age, and maternal body mass index at pre-pregnancy. In addition to the normotensive term subjects, we collected preterm normotensive control samples from pregnancies with a premature rupture of the membrane due to a breech presentation or a previous caesarean section without evidence of intrauterine infection. The early gestation placental tissues were obtained from elective surgical terminations of pregnancies. Clinical details of these subjects are presented in Table 1.

To avoid any possible effects of labor on NECTIN4 expression, only placental samples that were obtained through Caesarean section from women who had not undergone labor were analyzed. A central area of chorionic tissue was dissected and the maternal deciduas and amnionic membranes were removed from these samples. After vigorous washing of the maternal blood with saline, tissues were immediately frozen in liquid nitrogen and stored until use. Informed consent was obtained from each patient and this study was approved by the Ethical Review Board for Clinical Studies at Fujita Health University.

Table 1 Characteristics of the subjects with normotensive pregnancies and severe pre-eclampsia

\begin{tabular}{|c|c|c|c|}
\hline & Normotensive Pregnancy & Severe pre-eclampsia & $P$ Value \\
\hline & $N=25$ & $N=22$ & \\
\hline Maternal age (y) & $29.4 \pm 5.8^{a}$ & $30.2 \pm 3.6$ & n.s. \\
\hline Gestational age (wks) & $33.2 \pm 5.1$ & $32.9 \pm 3.8$ & n.s. \\
\hline Parity (n) & $0.71 \pm 0.76$ & $0.22 \pm 0.42$ & $P<0.05$ \\
\hline Systolic BP (mmHg) & $113.0 \pm 10.0$ & $169.6 \pm 14.5$ & $P<0.05$ \\
\hline Diastolic BP (mmHg) & $66.8 \pm 9.8$ & $105.9 \pm 13.9$ & $P<0.05$ \\
\hline Proteinuriab $^{b}$ & $0(0 \%)$ & $22(100 \%)$ & $P<0.05$ \\
\hline Body mass index $(\mathrm{BMI})^{\mathrm{C}}$ & $22.3 \pm 4.6$ & $22.3 \pm 7.5$ & n.s. \\
\hline Placental weight (g) & $480.0 \pm 244.1$ & $312.9 \pm 126.7$ & $P<0.05$ \\
\hline Birth weight (g) & $1984.9 \pm 905.7$ & $1585.5 \pm 722.6$ & $P<0.05$ \\
\hline Birth weight coefficient & $1.012 \pm 0.129$ & $0.742 \pm 0.215$ & $P<0.05$ \\
\hline $\mathrm{Hb}(\mathrm{g} / \mathrm{dl})$ & $10.9 \pm 0.9$ & $12.0 \pm 1.9$ & n.s. \\
\hline Platelet count $\left(\times 10^{4} / \mathrm{ul}\right)$ & $25.2 \pm 3.8$ & $15.4 \pm 8.2$ & $p<0.05$ \\
\hline GOT (IU/I) & $18.3 \pm 7.5$ & $39.5 \pm 31.7$ & $p<0.05$ \\
\hline GPT (IU/I) & $15.4 \pm 16.4$ & $25.7 \pm 15.8$ & n.s. \\
\hline LDH (IU/I) & $206.8 \pm 36.1$ & $333.4 \pm 98.1$ & $p<0.05$ \\
\hline
\end{tabular}

$\mathrm{Hb}$ Hemoglobin, GOT Glutamate oxaloacetate transaminase, GPT Glutamate pyruvate transaminase, LDH Lactate dehydrogenase

${ }^{a}$ Data are given as the mean \pm standard deviation (SD)

${ }^{b} \geq 2 \mathrm{~g}$ in a $24 \mathrm{~h}$ collection

cpre-pregnancy 


\section{Real-time RT-PCR}

Total RNA was extracted from chorionic villous tissue samples using an RNeasy mini-kit (Qiagen, Valencia, $\mathrm{CA}$ ), according to the manufacturer's instructions. To quantify the NECTIN4 gene expression levels, we performed real-time RT-PCR analyses using an ABI PRISM 7700 Sequence Detection System (Perkin-Elmer, Foster City, CA). A Superscript First-strand Synthesis System for RT-PCR (Invitrogen, Grand Island, NY) using random primers was employed to produce single strand cDNA from total RNA. PCR primers and TaqMan probes (Hs00363974_m1) were obtained from Applied Biosystems GmbH (Weiterstadt, Germany). The housekeeping gene 18S rRNA (Hs99999901_s1) was used to normalize mRNA concentrations, since expression of other genes widely used as controls are often regulated by estrogen. RT-PCR reactions were performed in triplicate using a TaqMan EZ RT-PCR Kit (Perkin-Elmer) in a final volume of $25 \mu \mathrm{l}$. The cycling conditions were $2 \mathrm{~min}$ at $50{ }^{\circ} \mathrm{C}, 30 \mathrm{~min}$ at $60{ }^{\circ} \mathrm{C}$, and $1 \mathrm{~min}$ at $95{ }^{\circ} \mathrm{C}$ for $\mathrm{RT}$, followed by 40 cycles of $15 \mathrm{~s}$ at $95^{\circ} \mathrm{C}$, and $1 \mathrm{~min}$ at $60^{\circ}$ $\mathrm{C}$ for PCR amplification.

\section{Antibodies}

Polyclonal goat antibodies raised against the C-terminal cytoplasmic domain of human nectin-4 was used for immunostaining and western blotting (AF2659; R\&D, Minneapolis, MN). In addition, rabbit polyclonal anti-human nectin- 4 antibodies were raised against amino acid residues 399-415 (CRRLHSHHTDPRSQPEES) and residues 463-479 (CPGSGRAEEEEDQDEGIK) within the cytoplasmic domain of human nectin-4. The resulting antisera were affinity purified on columns coupled to the peptide. To detect cells of the trophoblast lineage, anti-pancytokeratin monoclonal antibodies (Nichirei, Tokyo, Japan) were used.

\section{Western blot analysis}

Total cell lysates from placental tissue were prepared using T-PER (Pierce, Rockford, IL) and the proteins were separated by SDS-PAGE in 14\% Tris-glycine gels (TEFCO, Tokyo, Japan). After electrophoresis, the proteins were blotted onto a nitrocellulose membrane and blocked with 5\% skimmed milk powder diluted in Tris-buffered saline (TBS) with $0.05 \%$ Tween 20 . Membranes were incubated with diluted antibody preparations overnight at $4{ }^{\circ} \mathrm{C}$. After washing the next day, membranes were incubated with horseradish peroxidase (HRP)-conjugated affinity-purified donkey anti-rabbit or anti-goat IgG antibody (Jackson ImmunoResearch Laboratories, West Grove, PA) for $1 \mathrm{~h}$ at room temperature. The blots were then developed using SuperSignal (Pierce) and images were captured using Light-Capture with a cooled CCD camera (ATTO,
Tokyo, Japan). MagicMark XP Western Protein Standard (Invitrogen) and Precision Plus Protein Standards (BIO-RAD) were used as size markers. Recombinant human nectin-4 (H00081607-Q01, Abnova) and nectin4293 T cell transient overexpression lysate (H00081607T01, Abnova) were also used. For semi-quantitative analysis, the membranes were reprobed with an anti- $\beta$-actin antibody (Sigma-Aldrich, St. Louis, MO) as an internal control for the relative loading of the samples.

\section{Immunostaining}

Placental samples were fixed with $10 \%$ formaldehyde overnight, and then embedded with paraffin. Tissue sections $(2 \mu \mathrm{m})$ were placed on silane-coated slides and dried in a conventional oven at $60{ }^{\circ} \mathrm{C}$ for $24 \mathrm{~h}$. After deparaffinization and rehydration, endogenous peroxidase activity was blocked with $0.3 \%$ hydrogen peroxide in methanol. Polyclonal goat or rabbit antibodies against human nectin-4 were used for detection. Bound antibodies were detected with a peroxidase-based method using Simple Stain MAX-PO (Nichirei, Tokyo, Japan) with 3,3-diaminobenzidine as a substrate. Non-specific goat or rabbit IgG (Zymed, San Francisco, CA) was used as the negative control. Counterstaining was performed with Mayer's hematoxylin solution. We performed immunostaining for 8 placental samples from preeclampsia and 8 controls. We stained three sections for each sample, and we examined 5 fields per each section. The immunostained specimens were examined by an observer who was not aware of the expression data and clinical outcomes. The signal intensities were evaluated by a method proposed previously [19].

\section{Overexpression of NECTIN4}

The cDNA encoding human NECTIN4 was chemically synthesized and cloned into the pCMV-3Tag- 8 vector. HTR-8/SVneo, a widely-used first trimester human trophoblast cell line, was purchased from Dr. Charles Graham at Queen's University (Kingston, Ontario, Canada). The vector was transfected into HTR-8 cells using Lipofectamine 3000 (Thermo Fisher Scientific). Clones stably overexpressing the NECTIN4 gene were selected using $200 \mu \mathrm{g} / \mathrm{ml}$ hygromycin. Expression levels were assayed by western blotting with anti-FLAG or anti-nectin-4 antibodies.

\section{Matrigel invasion assay}

HTR-8/SVneo cells overexpressing the NECTIN4 gene or negative control were seeded into the upper chamber of a 24-well transwell plate with an $8.0-\mu \mathrm{m}$ pore size coated with Matrigel Basement Membrane Matrix (BioCoat Matrigel Invasion Chamber, Corning). Cells remaining in the upper chamber were removed using a cotton swab and the membranes were inverted and 
stained with toluidine blue and quantified. The invasion index was calculated, in accordance with the manufacturer's instructions, as the ratio of the cells invading through the matrigel membrane to those migrating through the control membrane.

\section{Cytotoxicity assay by NK cell line}

NK-92MI were purchased from the ATCC (Manassas, VA). NK-92MI, an IL-2-independent natural killer cell line, is cytotoxic to a wide range of cells. To evaluate the level of cytotoxity, we used a CytoTox $96^{\circ}$ Non-Radioactive Cytotoxicity Assay (Promega, Madison, WI). In brief, HTR-8/SVneo cells overexpressing the NECTIN4 gene or a negative control were prepared as target cells at a density of $2.0 \times 10^{5}$ cells $/ \mathrm{ml}$. NK-92MI cells were prepared at a density of $5.0 \times 10^{5}$ cells $/ \mathrm{ml}$ as effector cells and added to the target cell culture cells at a 2.5:1 effector-to-target $(\mathrm{E}: \mathrm{T})$ ratio. The cells were then co-cultured for $4 \mathrm{~h}$ at $37^{\circ} \mathrm{C}$. Cell lysis was detected by the release of lactate dehydrogenase (LDH) using an LDH cytotoxicity assay kit. The percentage of cytotoxicity was calculated in accordance with the manufacturer's instructions (Promega).

\section{Genomic sequencing of NECTIN4 gene}

Genomic DNA was extracted from the placentas using a commercially available kit following the manufacturer's protocol (Qiagen, Frankfurt, Germany). A total of 41 pre-eclampsia samples and 28 control samples from a normal pregnancy were used. The NECTIN4 gene ([hg19] chr1:161,040,781-161,059,385) is about $18 \mathrm{~kb}$ in size and consists of 9 exons. We divided the entire NECTIN4 genomic region into three subregions that were amplified using specific primers and KAPA Long Range HotStart DNA Polymerase (KAPA Biosystems, Wilmington, MA). The primers used in this study are listed in Table 2. Long-range PCR was performed under the following conditions: initial denaturation of $95{ }^{\circ} \mathrm{C}$ for $3 \mathrm{~min}$ followed by 35 cycles of $94{ }^{\circ} \mathrm{C}$ for $15 \mathrm{~s}, 62{ }^{\circ} \mathrm{C}$ for $15 \mathrm{~s}$ and $68^{\circ} \mathrm{C}$ for $8 \mathrm{~min}$. The three PCR products were mixed to equimolar concentrations. Pooled DNA libraries were then prepared using a Nextera XT DNA Sample Preparation Kit according to the manufacturer's protocol (Illumina, San Diego, CA) and sequenced using MiSeq Reagent Kit v2 (300 cycles)

Table 2 PCR primers used for genomic sequencing

\begin{tabular}{lll}
\hline Positions & Forward primers & Reverse primers \\
\hline chr1:161,040,096- & GACTAGAGGACCTTAAAT & GGGTTCTCAGCAGA \\
$161,047,207$ & CCTCCC & TTGGTGAGATG \\
chr1:161,046,599- & GCCTGATTITCAAAGGTG & CCTITCTCACCCCA \\
$161,054,779$ & TAACAATCCTAC & GACTCACCCACATA \\
chr1:161,054,085- & ATGATTCCGTGTGCATGTC & GTCTGAGCAAACCA \\
$161,059,885$ & ACACCCT & TGAGACTAAGT \\
\hline
\end{tabular}

with $150 \mathrm{bp}$ paired-end sequencing (Illumina). Sequence reads were mapped to the human reference sequence (RefSeq: NM_030916.2). The identified variants were confirmed by Sanger sequencing.

\section{Statistical analysis}

Intergroup comparisons were made using the Student's $t$ test or one way analysis of variance method and $P$ values of less than 0.05 were considered statistically significant.

\section{Results \\ NECTIN4 mRNA and protein are upregulated in a pre- eclamptic placenta}

We performed quantitative RT-PCR for NECTIN4 using 20 placental samples from severe pre-eclampsia patients and 20 from subjects with an uncomplicated pregnancy. The NECTIN4 transcript level was found to be significantly increased in placentas from the pre-eclampsia cases (Fig. 1, Additional file 1: Figure S1). We performed western blotting to then examine the expression of nectin-4 protein. Although the molecular weight of nectin-4 is $55.5 \mathrm{kDa}$ based upon its amino acid sequence, total cell lysates from placental samples showed two expressed nectin-4 isoforms of $55.5 \mathrm{kDa}$ and $75 \mathrm{kDa}$ (Fig. 2a, left panel). To confirm that these two species were derived from nectin-4, we used a different nectin-4 antibody and obtained similar immunoblotting results (Additional file 2: Figure S2). To evaluate the nectin-4 protein level, the western blots were subjected to semi-quantitative analyses using $\beta$-actin as an internal control. Both isoforms of the nectin- 4 protein were found to be more abundant in pre-eclamptic placentas (Fig. 2b).

\section{Nection-4 protein is produced by syncytiotrophoblasts in the placenta}

To localize the nectin- 4 protein within the placental tissue, we examined placental histological specimens stained with a rabbit polyclonal anti-nectin- 4 antibody of confirmed specificity on a western blot. This analysis revealed signals in the cytoplasm and stronger signals at the cell membrane on the apical side in the syncytiotrophoblast cells within the chorionic villi from uncomplicated term pregnancies (Fig. 3a and b, Additional file 3: Figure S3). Similar observations were made using alternate goat anti-nectin-4 antibodies (Fig. 3c). In preeclamptic placentas however, the nectin- 4 protein signals in the syncytiotrophoblasts were stronger than those detected in uncomplicated pregnancies. Notably, the signal intensities at the apical cell membranes of the syncytiotrophoblast cells in the pre-eclamptic subjects were much stronger than those in the normal pregnancy controls (Fig. 3d, e and f). 


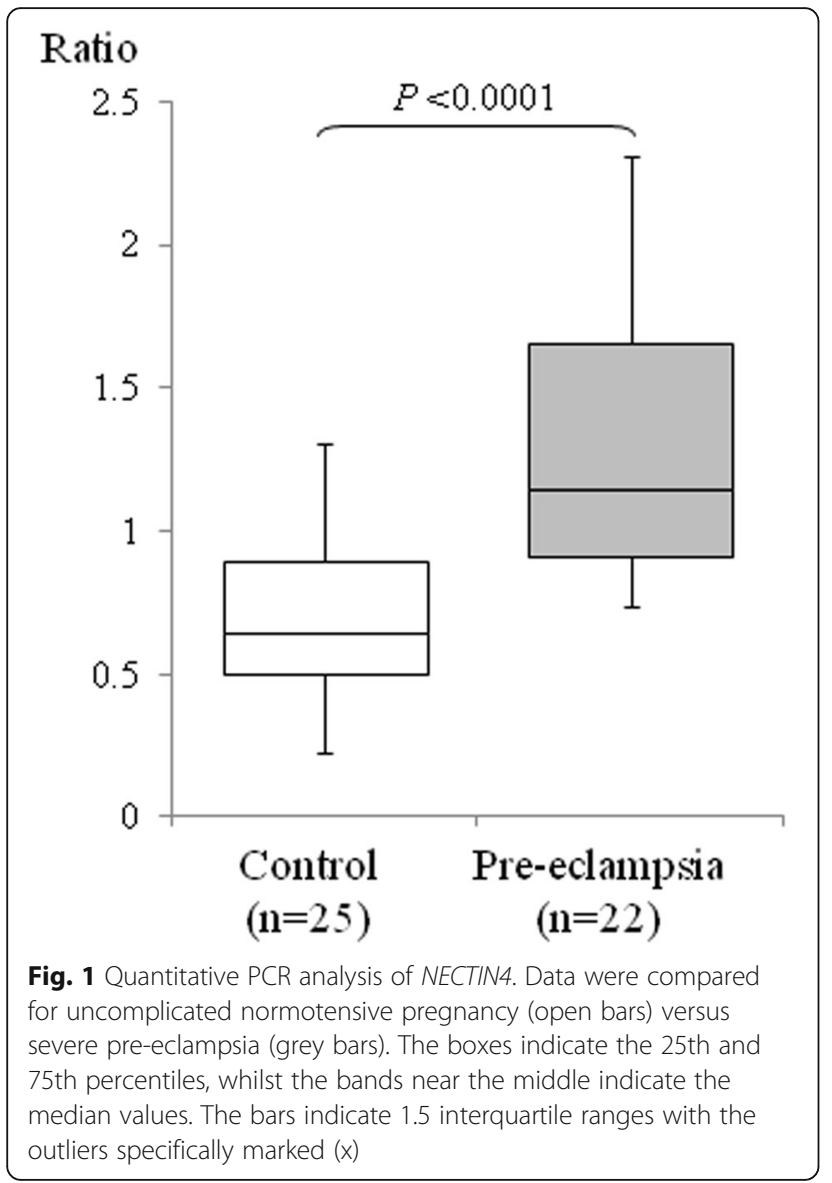

Cytotrophoblast cells were also positive for the nectin-4, which was more prominent in samples from early gestation (Fig. 4a and b). Further, we observed the presence of nectin-4-positive cells in maternal decidua (Fig. 4c and d).
These cells might be extravillous trophoblasts since they were also positive for cytokeratin (Fig. $4 \mathrm{e}$ and f). The signal intensity was stronger in samples from pre-eclampsia than from controls (Fig. 4c and d).

\section{Nectin-4 protein overexpression does not affect cell migration}

Since HTR-8/SVneo cells do not strongly express NECTIN4 (data not shown), we produced a nectin-4 overexpressing HTR-8/SVneo cell line to use as a model system for invasive trophoblasts in pre- eclampsia (Additional file 4: Figure S4). In the early gestational period when placentation occurs, fetal trophoblasts that have invaded the basal membrane of the maternal uterus and then migrate to the uterine interstitium. These cells then migrate to the uteroplacental spiral artery and finally replace the maternal endovascular endothelial cells [20]. It has been proposed that the failure of this vascular remodeling system may lead to the onset of pre-eclampsia [20]. We compared the cell migration ability of trophoblasts overexpressing nectin-4 relative to control trophoblasts. However, the up-regulation of NECTIN4 did not affect the invasiveness of the HTR- 8 cells in the basal membrane-type extracellular matrix (Fig. 5a).

We also speculate that invading fetal trophoblasts may be a target for the maternal immune system, such as NK cells, and that the migration of these cells might be strictly regulated by natural immunity. We thus compared NK cell cytotoxicity towards trophoblasts overexpressing nectin-4 relative to control trophoblasts. Trophoblasts overexpressing nectin- 4 showed more sensitivity to the cytotoxic effects of NK cells (Fig. 5b).

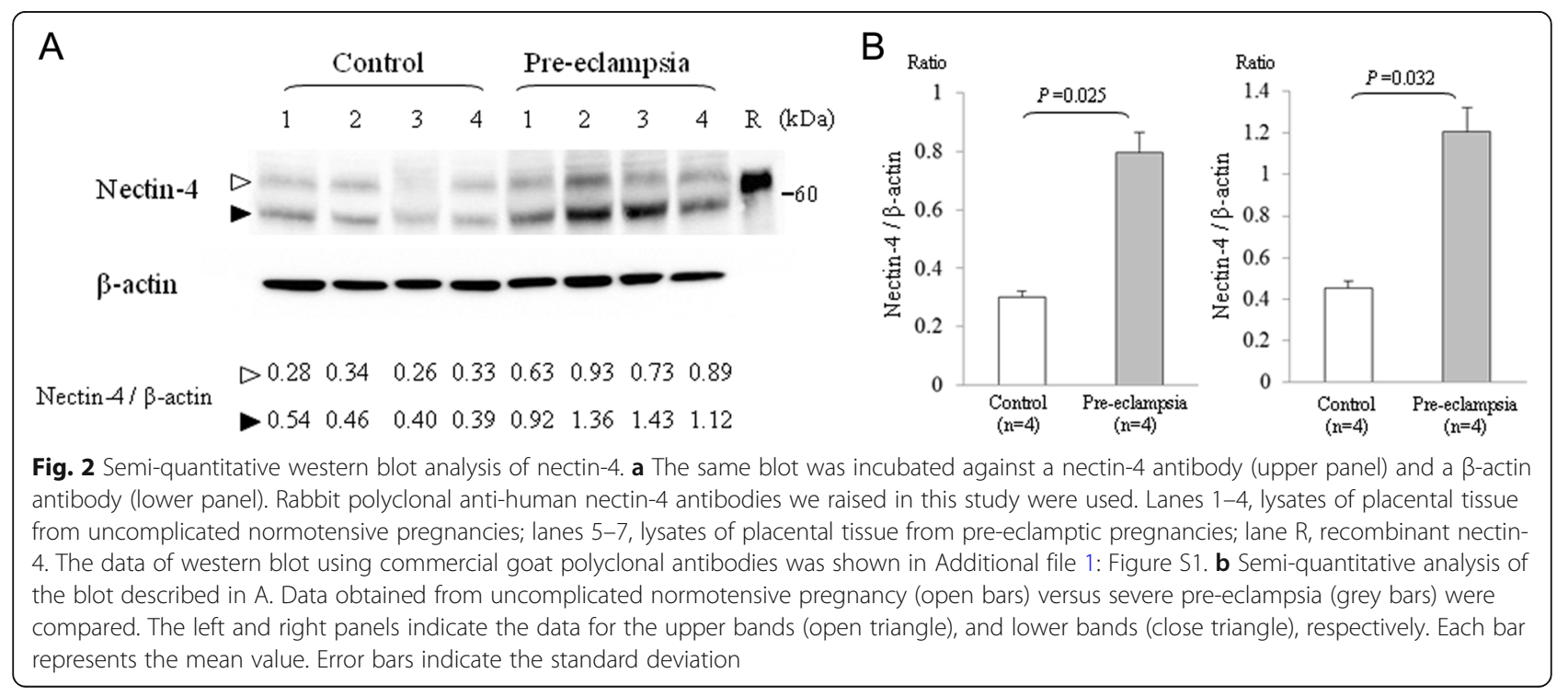




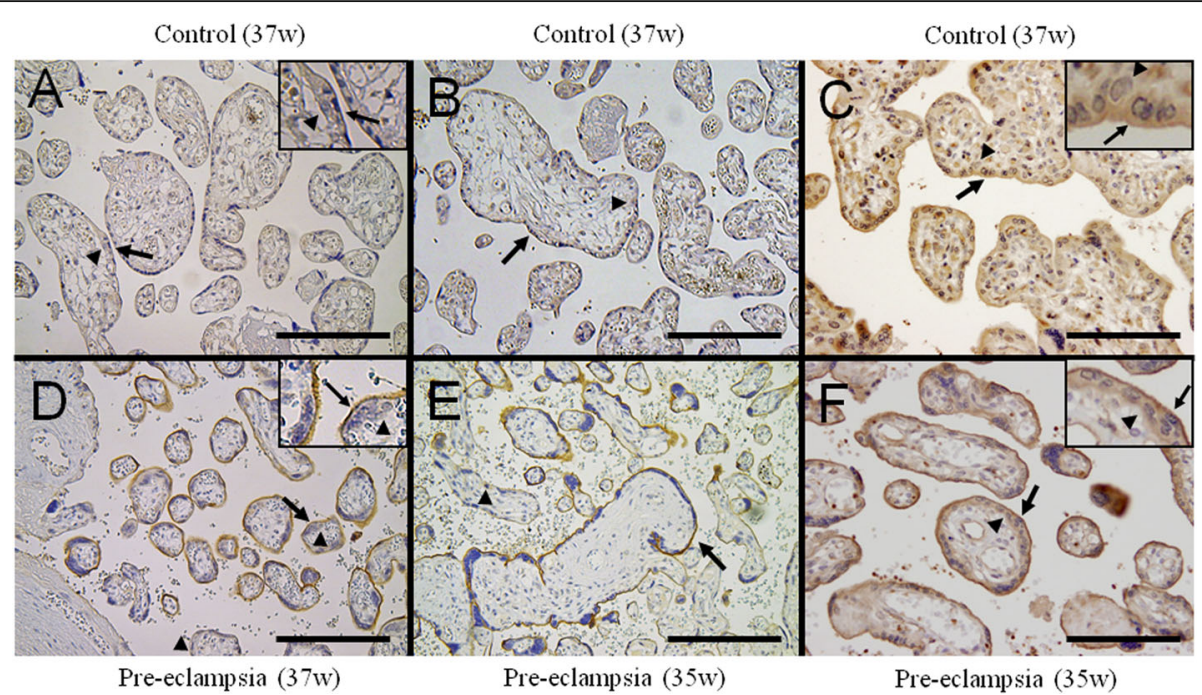

Fig. 3 Nectin-4 immunostaining of placental tissue sections. Polyclonal rabbit antibodies raised against the cytoplasmic domain of the human nectin-4 (a, b, $\mathbf{d}$ and $\mathbf{e}$ ) or polyclonal goat antibodies raised against the C-terminal domain of the human nectin-4 (c and $\mathbf{f}$ ) were used. Positive staining was apparent in the cytoplasm and cell membrane at the apical side of the syncytiotrophoblasts (arrows). Cytotrophoblasts were also positive (arrowheads, insets). The nectin-4 signals were much stronger in pre-eclampsia (d, e and $\mathbf{f}$ ) compared with uncomplicated normotensive pregnancy (a, b, and $\mathbf{c})$. Original magnifications a-f: 400 x. Scale bars, $100 \mu \mathrm{m}$

\section{The NECTIN4 gene is not mutated in pre-eclamptic} placental tissue

Given the possibility that the up-regulation of NECTIN4 might be the primary etiology of pre-eclampsia, we hypothesized that mutations in this gene may underlie its up-regulation. We sequenced an $18 \mathrm{~kb}$ genomic region that contains the promoter region and 9 exons of the
NECTIN4 gene but found no rare variants in placental samples from pre-eclampsia patients (data not shown).

\section{Discussion}

We have analyzed the overexpression of the NECTIN4 gene, both at the RNA and protein levels, in pre-eclamptic and normal placentas to test whether alterations in the

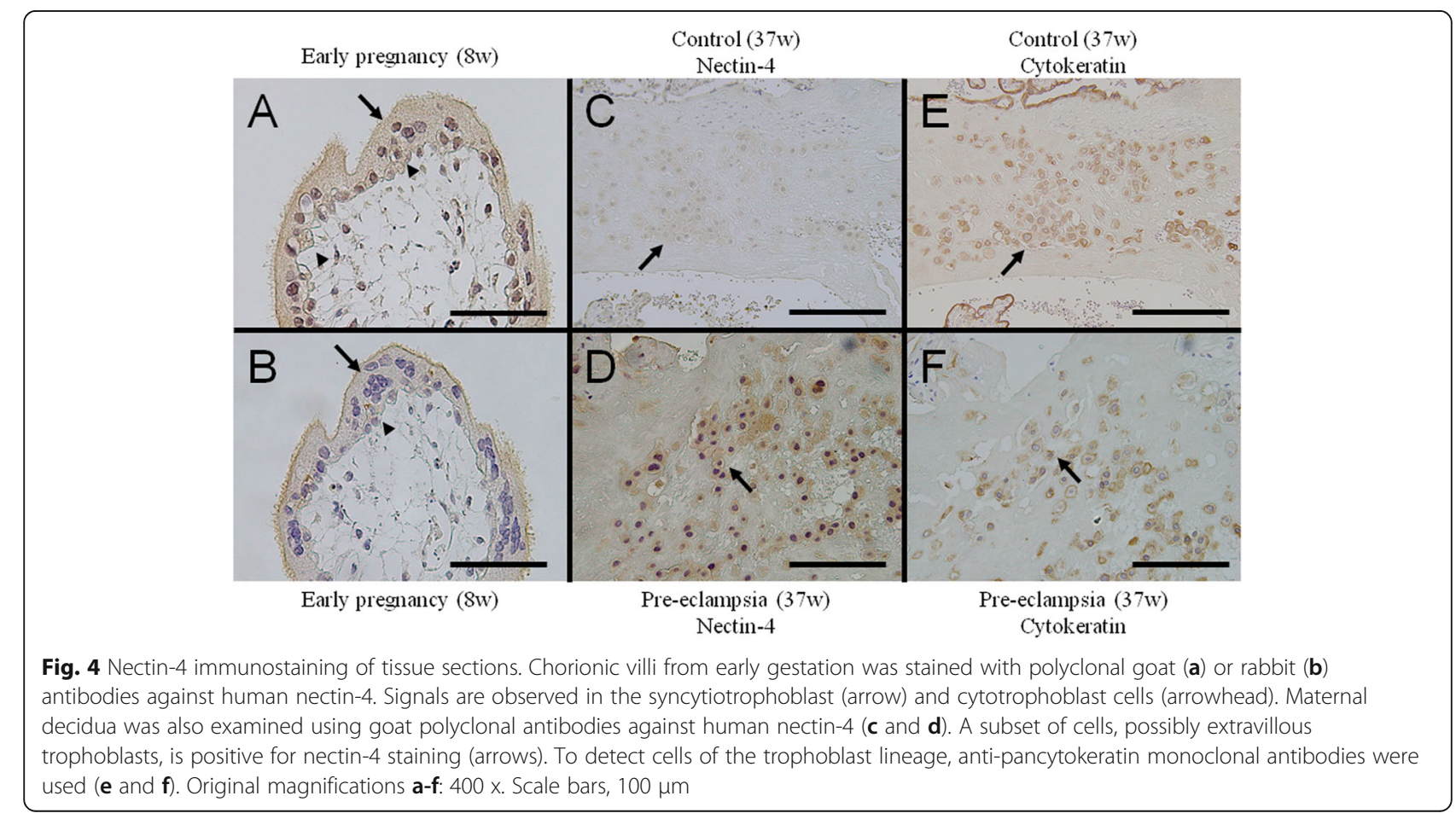



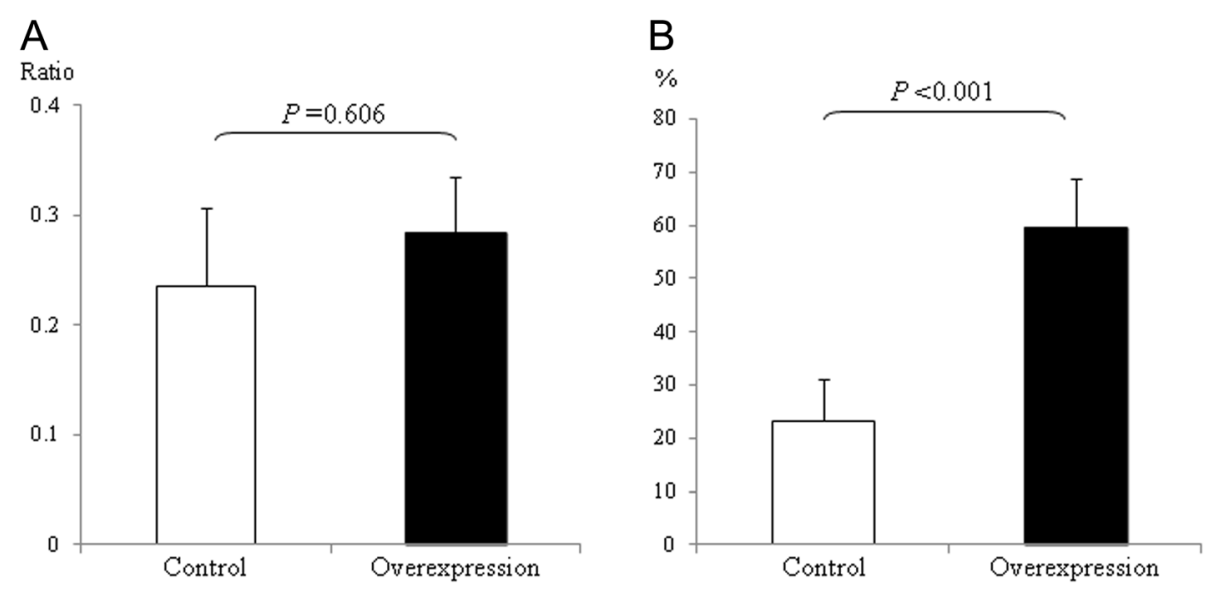

Fig. 5 Overexpression of the NCTIN4 gene in HTR-8 cell lines. a Invasion assay. Vertical axis indicates the ratio of cells invading through the matrigel membrane to those migrating through the control membrane. b NK cell cytotoxicity assay. Vertical axis indicates the percentage cytotoxicity calculated using an LDH cytotoxicity assay. Data obtained from control HTR-8 cells (open bars) versus HTR-8 cells overexpressing nectin-4 (black bars) were compared. Each bar represents the mean value. Error bars indicate the standard deviation

expression of this gene underlie the etiology of pre-eclampsia. Although other members of the nectin family are expressed ubiquitously, NECTIN4 is specifically expressed in the skin, esophagus, urinary bladder and placenta. The nectins are known to be adhesion molecules that may have key functions at adherens junctions and tight junctions [9]. However, our current data indicate that the nectin- 4 protein is localized at the apical cell membrane of syncytiotrophoblasts, suggesting different functional properties from other nectins. Further, we observed the presence of nectin-4-positive cells in maternal decidua, which might be extravillous trophoblasts. It is thus feasible to suspect a functional linkage between nectin-4 and trophoblast invasion in the placental bed and in maternal uteroplacental arteries [20]. We do not know however if invasive trophoblasts actually express nectin- 4 in the plasma membrane during early gestation. We hypothesize from our current analysis that trophoblast invasion is regulated by the surface expression of nectin-4 on these cells.

It has long been accepted that placentation is abnormal in pre-eclampsia [21]. Trophoblast invasion of the interstitial uterine compartment is frequently shallow, and invasion into the spiral artery is often incomplete, during a pre-eclamptic pregnancy. Likewise, the impaired invasion of trophoblasts is believed to underlie the etiology of this disorder. Our current results indicate that nectin-4 expression is upregulated at the apical cell membrane of the syncytiotrophoblasts in pre-eclampsia. The overexpression of nectin-4 in extravillous trophoblast in maternal decidua might reflect invasive trophoblast in early gestation. We hypothesized that trophoblast invasion might be impaired in pre-eclampsia by the overexpression of NECTIN4.
However, an invasion assay using HTR-8 cell lines did not support this possibility.

In further experiments however, HTR-8 cells stably overexpressing exogenous NECTIN4 were significantly more sensitive to NK cell cytotoxicity than control HTR-8 cells. These data suggest the possibility that the nectins might regulate NK-target interactions and that the impairment of these interactions might induce the onset of pre-eclampsia. Consistently, there is some evidence that nectins play an important role in the recognition of target cells by NK cells. It has been reported previously that NK cells recognize and kill human glioblastoma cells that express high levels of nectin-2 [22]. Another study has demonstrated that the interaction of nectin- 2 and its ligand inhibits NK cell cytotoxicity [23]. Similarly, it has been reported that the interaction of nectin- 4 and its ligand might activate NK cell cytotoxity towards trophoblasts, leading to their impaired invasion [24, 25].

It was demonstrated recently that mutations in $N E C$ TIN4 resulted in ectodermal dysplasia-syndactyly syndrome in humans [26, 27]. This is a rare autosomal recessive disorder that might be caused by a loss-of-function of NECTIN4. We thus hypothesized that this disorder and pre-eclampsia might represent allelic heterogeneity and the mutation in NECTIN4 may cause its overexpression of NECTIN4 and lead to the onset of pre-eclampsia. However, our current data did not reveal any NECTIN4 variants in pre-eclamptic placentas. Taken together, our present data suggest the possibility that some unknown factors induce nectin-4 protein overexpression in trophoblasts that might cause abnormal placentation via aberrant immunity, and ultimately a pre-eclamptic pregnancy. On the 
other hand, it is also possible that the elevated expression of the nectin- 4 is secondary to the dysfunction of syncytiotrophoblast cells.

\section{Conclusion}

Our current data highlight an old proposition i.e. the direct involvement of NK cells in the etiology of preeclampsia. Further detailed analysis of the functional roles of nectin- 4 in placentation will be needed to properly assess the association of its overexpression with the etiology of pre-eclampsia.

\section{Additional files}

Additional file 1: Figure S1. Quantitative PCR analysis of NECTIN4. Data were compared for uncomplicated normotensive pregnancy (open bars) versus severe pre-eclampsia (grey bars). Among the uncomplicated normotensive pregnancy, data were also compared for pre-term $(\leq 36 \mathrm{wks})$ versus term $(\geq 37 \mathrm{wks})$. The boxes indicate the 25 th and 75 th percentiles, whilst the bands near the middle indicate the median values. The bars indicate 1.5 interquartile ranges with the outliers specifically marked (x). (TIF $2224 \mathrm{~kb}$ )

Additional file 2: Figure S2. Western blot analysis of nectin-4. Polyclonal goat antibodies raised against the C-terminal cytoplasmic domain of human nectin-4 were used (R\&D). The bands indicated by the open and closed triangles correspond with those shown in Fig. 2. (TIF $2218 \mathrm{~kb})$

Additional file 3: Figure S3. Negative control for immunostaining. Non-specific polyclonal lgG was used. (TIF 11898 kb)

Additional file 4: Figure S4. Western blot analysis of cell lines with overexpression of nectin-4. Left panel indicates the data for anti-FLAG antibodies, while right panel indicates the data for anti-nectin 4 antibodies. Lane $\mathrm{N}$, negative control (no transfection); lane $\mathrm{P}$, positive control (transient expression); lane $\mathrm{O}$, stable line with overexpression of nectin-4. (TIF $3354 \mathrm{~kb}$ )

\section{Abbreviations}

F-actin: Filamentous-actin; HRP: Horseradish peroxidase; LDH: Lactate dehydrogenase; NK: Natural killer; PVRL: Poliovirus receptor-like receptors; RTPCR: Reverse transcription polymerase chain reaction; TBS: Tris-buffered saline

\section{Acknowledgements}

We thank S. Ota and M. Suzuki for technical assistance.

\section{Funding}

This study was supported by the Ogyaa Donation Foundation from the Japan Association of Obstetricians and Gynecologists, and by grants-in-aid for Scientific Research from the Ministry of Education, Culture, Sports, Science, and Technology, Japan (16 K11117, 15H04710) and from the Ministry of Health, Labour and Welfare, Japan (H27-nanchitou (nan)-ippan-024).

\section{Availability of data and materials}

The datasets used and/or analysed during the current study available from the corresponding author on reasonable request.

\section{Authors' contributions}

$\mathrm{Ml}$ and $\mathrm{HN}$ conceived the project, participated in its design and coordination, and analyzed the data. MI, MT, AK and TK carried out the overall molecular experiments including the genomic sequencing. YS, YN, $\mathrm{AO}$ and $\mathrm{JM}$ carried out the operations, and participated in the design and coordination of the study. KS carried out the immunostaining, and evaluated of signal intensity in the placental specimens. HK conceived the project, participated in its design and coordination, and helped to draft the manuscript. TS and TF participated in the design and coordination of the project and helped to draft the manuscript. All authors (MI, HN, MT, AK, YS,
YN, AO, JM, TK, KS, TS, HK and TF) reviewed and approved the final manuscript.

Ethics approval and consent to participate

All clinical samples were collected at the Department of Obstetrics and Gynecology, Fujita Health University, Japan. Informed consent was obtained from each patient and the study protocolwas approved by the Ethical Review Board for Human Genome Studies at Fujita Health University (Accession number 43 and 87, approved on February 23, 2005 and March 24 2010, respectively).

\section{Consent for publication}

The written informed consent was obtained from the participants for the publication of related clinical information.

\section{Competing interests}

The authors declare that they have no competing interests.

\section{Publisher's Note}

Springer Nature remains neutral with regard to jurisdictional claims in published maps and institutional affiliations.

\section{Author details}

${ }^{1}$ Department of Obstetrics and Gynecology, Fujita Health University School of Medicine, 1-98 Dengakugakubo, Kutsukake, Toyoake, Aichi 470-1192, Japan. ${ }^{2}$ Division of Molecular Genetics, Institute for Comprehensive Medical Science, Fujita Health University, Toyoake, Japan. ${ }^{3}$ Division of Morphology and Cell Function, Faculty of Medical Technology, Fujita Health University School of Health Sciences, Toyoake, Japan.

Received: 21 November 2017 Accepted: 4 September 2018

Published online: 14 September 2018

\section{References}

1. National Institutes of Health. Working group report on high blood pressure in pregnancy. Bethesda: NIH Publication No. 00-3029; 2000.

2. Roberts JM, Cooper DW. Pathogenesis and genetics of pre-eclampsia. Lancet. 2001:357(9249):53-6.

3. Cross JC. The genetics of pre-eclampsia: a feto-placental or maternal problem? Clin Genet. 2003;64(2):96-103.

4. Sibai B, Dekker G, Kupferminc M. Pre-eclampsia. Lancet. 2005:365(9461):785-99.

5. Chen DB, Wang W. Human placental microRNAs and preeclampsia. Biol Reprod. 2013:88(5):130

6. Jairajpuri DS, Almawi WY. MicroRNA expression pattern in pre-eclampsia. Mol Med Rep. 2016:13(3):2351-8.

7. Goulopoulou S, Davidge ST. Molecular mechanisms of maternal vascular dysfunction in preeclampsia. Trends Mol Med. 2015;21(2):88-97.

8. Laresgoiti-Servitje E. A leading role for the immune system in the pathophysiology of preeclampsia. J Leukoc Biol. 2013:94(2):247-57.

9. Takai Y, Miyoshi J, Ikeda W, Ogita H. Nectins and nectin-like molecules: roles in contact inhibition of cell movement and proliferation. Nat Rev Mol Cell Biol. 2008;9(8):603-15.

10. Reymond N, Fabre S, Lecocq E, Adelaïde J, Dubreuil P, Lopez M. Nectin4/ PRR4, a new afadin-associated member of the nectin family that transinteracts with nectin1/PRR1 through V domain interaction. J Biol Chem. 2001:276(46):43205-15.

11. Ikeda W, Nakanishi H, Miyoshi J, Mandai K, Ishizaki H, Tanaka M, et al. Afadin: a key molecule essential for structural organization of cell-cell junctions of polarized epithelia during embryogenesis. J Cell Biol. 1999;146(5):1117-32.

12. Mühlebach MD, Mateo M, Sinn PL, Prüfer S, Uhlig KM, Leonard VH, et al. Adherens junction protein nectin-4 is the epithelial receptor for measles virus. Nature. 2011;480(7378):530-3.

13. Fabre-Lafay S, Monville F, Garrido-Urbani S, Berruyer-Pouyet C, Ginestier C, Reymond $\mathrm{N}$, et al. Nectin-4 is a new histological and serological tumor associated marker for breast cancer. BMC Cancer. 2007:7:73.

14. Takano A, Ishikawa N, Nishino R, Masuda K, Yasui W, Inai K, et al. Identification of nectin-4 oncoprotein as a diagnostic and therapeutic target for lung cancer. Cancer Res. 2009;69(16):6694-703.

15. Boylan KL, Buchanan PC, Manion RD, Shukla DM, Braumberger K Bruggemeyer $C$, et al. The expression of Nectin- 4 on the surface of ovarian 
cancer cells alters their ability to adhere, migrate, aggregate, and proliferate. Oncotarget. 2017;8(6):9717-38.

16. Nishizawa H, Pryor-Koishi K, Kato T, Kowa H, Kurahashi H, Udagawa Y. Microarray analysis of differentially expressed fetal genes in placental tissue derived from early and late onset severe pre-eclampsia. Placenta. 2007;28: 487-97.

17. Nishizawa H, Ota S, Suzuki M, Kato T, Sekiya T, Kurahashi H, et al. Comparative gene expression profiling of placentas from patients with severe pre-eclampsia and unexplained fetal growth restriction. Reprod Biol Endocrinol. 2011;9:107.

18. American College of Obstetricians and Gynecologists, Task Force on Hypertension in Pregnancy. Hypertension in pregnancy. Report of the American College of Obstetricians and Gynecologists' task force on hypertension in pregnancy. Obstet Gynecol. 2013;122(5):1122-31.

19. van Diest PJ, van Dam P, Henzen-Logmans SC, Berns E, van der Burg ME, Green J, et al. A scoring system for immunohistochemical staining: consensus report of the task force for basic research of the EORTC-GCCG. European Organization for Research and Treatment of CancerGynaecological Cancer cooperative group. J Clin Pathol. 1997;50(10):801-4.

20. Kaufmann P, Black S, Huppertz B. Endovascular trophoblast invasion: implications for the pathogenesis of intrauterine growth retardation and preeclampsia. Biol Reprod. 2003;69(1):1-7.

21. Fisher SJ. Why is placentation abnormal in preeclampsia? Am J Obstet Gynecol. 2015;213(4 Suppl):S115-22.

22. Castriconi R, Daga A, Dondero A, Zona G, Poliani PL, Melotti A, et al. NK cells recognize and kill human glioblastoma cells with stem cell-like properties. J Immunol. 2009;182(6):3530-9.

23. Stanietsky N, Simic H, Arapovic J, Toporik A, Levy O, Novik A, et al. The interaction of TIGIT with PVR and PVRL2 inhibits human NK cell cytotoxicity. Proc Natl Acad Sci U S A. 2009;106(42):17858-63.

24. Saito S, Shiozaki A, Nakashima A, Sakai M, Sasaki Y. The role of the immune system in preeclampsia. Mol Asp Med. 2007;28(2):192-209.

25. Ahn H, Park J, Gilman-Sachs A, Kwak-Kim J. Immunologic characteristics of preeclampsia, a comprehensive review. Am J Reprod Immunol. 2011;65(4): 377-94

26. Brancati F, Fortugno P, Bottillo I, Lopez M, Josselin E, Boudghene-Stambouli $\mathrm{O}$, et al. Mutations in PVRL4, encoding cell adhesion molecule nectin-4, cause ectodermal dysplasia-syndactyly syndrome. Am J Hum Genet. 2010; 87(2):265-73.

27. Jelani M, Chishti MS, Ahmad W. Mutation in PVRL4 gene encoding nectin-4 underlies ectodermal-dysplasia-syndactyly syndrome (EDSS1). J Hum Genet. 2011;56(5):352-7.

Ready to submit your research? Choose BMC and benefit from:

- fast, convenient online submission

- thorough peer review by experienced researchers in your field

- rapid publication on acceptance

- support for research data, including large and complex data types

- gold Open Access which fosters wider collaboration and increased citations

- maximum visibility for your research: over $100 \mathrm{M}$ website views per year

At BMC, research is always in progress.

Learn more biomedcentral.com/submissions 